\title{
Patients' satisfaction with care after stroke: relation with characteristics of patients and care
}

\author{
W J M Scholte op Reimer, R J de Haan, M Limburg, G A M van den Bos
}

\begin{abstract}
Objectives - To evaluate stroke patients' satisfaction with care received and to identify characteristics of patients and care which are associated with patients' dissatisfaction.

Design - Cross sectional study.
\end{abstract}

Setting - Sample of patients who participated in a multicentre study on quality of care in 23 hospitals in the Netherlands.

Patients - 327 non-institutionalised patients who had been in hospital six months before because of stroke.

Main measures - Data were collected on (a) characteristics of patients: sociodemographic status, cognitive function (mini mental state examination), disability (Barthel index), handicap (Rankin scale), emotional distress (emotional behaviour subscale of the sickness impact profile) and health perception; (b) characteristics of care: use of various types of formal care after stroke, unmet care demands perceived by patients, unmet care demands confirmed by their general practitioners, continuity of care, and secondary prevention, and (c) patients' satisfaction with care received.

Results - $40 \%$ of the study sample were dissatisfied with at least one type of care received. Multivariate analyses showed that unmet care demands perceived by patients (odds ratio (OR) $3.2,95 \%$ confidence interval (95\% CI) 1.8 - 5.7) and emotional distress (OR 1.8, 95\% CI 1.13.0) were the main variables associated with dissatisfaction.

Conclusions - Patients' satisfaction was primarily associated with emotional distress and unmet care demands perceived by patients. No association was found between patients' satisfaction on the one hand and continuity of care or secondary prevention on the other; two care characteristics that are broadly accepted by professional care givers as important indicators of quality of long term care after stroke.

Implications - In view of these findings discussion should take place about the relative weight that should be given to patients' satisfaction as an indicator of quality of care, compared with other quality indicators such as continuity of care and technical competence. More research is needed to find which dimensions of quality of care are considered the most important by stroke patients and professional care givers.

(Quality in Health Care 1996;5:144-150)
Keywords: stroke, patients' satisfaction, quality of care

\section{Introduction}

In evaluating the quality of care, growing attention is given to patients' opinions of health care. It has been argued frequently that, besides quality of life or other functional health outcomes, patients' satisfaction is an important indicator of the quality of long term comprehensive care..$^{1-3}$ Furthermore, satisfaction helps patients to continue with their treatment. ${ }^{145}$ However, it seems from these review articles by Lewis, Williams, and Cleary and McNeil, ${ }^{145}$ that despite the interest in measuring patients' satisfaction, conceptual and methodological problems are not yet resolved. Studies on the determinants of patients' satisfaction are inconsistent. Factors thought to be related to satisfaction include patients' sociodemographic characteristics, physical and psychological state, attitudes, and expectations of health care, as well as structure, process, and outcome of care, but there is no consensus about which of these factors is most important. ${ }^{45}$

It has been argued that patients can provide a valid assessment of quality of care and that bias from personal characteristics is not strong enough to invalidate patients' ratings. ${ }^{6}$ On the other hand, patients' and care givers' perceptions of quality of care have been found to differ considerably. ${ }^{7}$ Some of these differences may be attributable to dissimilarity in the criteria which patients and professionals use for quality assessment. However, questions are also raised about the extent to which patients are competent to judge certain aspects of care. ${ }^{57}$ Poor practice, such as the use of contaminated needles, may go unnoticed and good practice, especially if it involves painful or time consuming procedures, may be criticised. Some authors even argue that patients' assessments show more about the patients' quality of life than about the quality of care itself. ${ }^{8}$ For example, it has been found that a patient's impaired health is associated with dissatisfaction with care received. ${ }^{159}$

Stroke is one of the most disabling diseases in the community. The annual incidence of stroke in The Netherlands is estimated at 174/ $100000 .{ }^{10}$ On the basis of demographic changes absolute stroke numbers are expected to rise. ${ }^{11}$ About $80 \%$ of the patients admitted to hospital with stroke are discharged home,${ }^{12}$ and many of them depend on multidisciplinary and long term care facilities. ${ }^{13}$

In view of the current debates the aim of our study was to describe the satisfaction with care among patients who had had a stroke six months before, and to identify characteristics 
of patients and care that are associated with the satisfaction. In the choice of care characteristics we focused especially on two often used aspects of long term care: continuity of care and technical competence in secondary prevention. These care characteristics are broadly accepted by professional care givers as important indicators of quality of long term care after stroke. ${ }^{13-15}$

\section{Patients and methods}

STUDY GROUP

The study group consisted of noninstitutionalised patients who had had a stroke six months before. These patients were the survivors of an original cohort of 760 consecutively admitted stroke patients who participated in a multicentre quality of care study in 23 hospitals in The Netherlands.

\section{COLLECTION OF DATA}

Six months after stroke, the patients were interviewed by trained research assistants with the aid of a semistructured questionnaire. Additional data were collected from the patients' general practitioners by means of a postal questionnaire.

\section{MEASURES}

Table 1 shows types of assessment of patients, their care, and their satisfaction. Data were collected on (a) characteristics of patients: sociodemographic characteristics (age, sex, and living arrangement), functional health status (cognitive function, disability, handicap), emotional distress, and perception of health; (b) characteristics of care: use of various types of formal care after stroke, unmet care demands perceived by patients, unmet care demands confirmed by their general practitioners, continuity of care, and technical competence; and (c) patients' satisfaction with care received.

\section{Characteristics of patients}

Cognitive function was assessed with the mini mental state examination ${ }^{16}$ and disability in activities of daily living (ADL) with the Barthel index. ${ }^{17}$ Handicap, defined as any limitation in the patient's social role, was measured with the modified Rankin scale, ${ }^{18}$ emotional distress with the emotional behaviour subscale of the sickness impact profile, ${ }^{19}$ and global level of perceived health with a single question "how would you rate your present health?"

\section{Characteristics of care}

To examine care characteristics we collected data on various types of regular professional healthcare services used between hospital discharge and six months after stroke: general practitioner care, physiotherapy, occupational therapy, speech therapy, mental care, social care, nursing care, home help, and day care. To enhance the reliability of data collection, a definition and an example of each care service was included in the questionnaire. Patients' perceived unmet care demands were assessed for each of the mentioned care services as "do you wish to receive (more) care?" Unmet care demands perceived by patients were subsequently submitted to their general practitioners as "is this patient in need (of more) of this specific type of care?" A positive answer was defined as an unmet care demand confirmed by the general practitioner. Care characteristics were also assessed in terms of continuity of care and technical competence. Continuity of care was defined as follows: (a) whether the general practitioner was informed about the patient's discharge from hospital or rehabilitation centre, and $(b)$ the number of weeks since last contact between patient and general practitioner (unadjusted and adjusted for the patient's level of disability). For technical competence we focused on secondary prevention: (a) general practitioner's awareness of the patient's hypertension, and (b) general practitioner's knowledge of the patient's use of antithrombotic medication (aspirin, dipyridamol, ticlopidine, or oral anticoagulation). The general practitioner's knowledge was considered accurate if the use of antithrombotic medication mentioned by him or her agreed with the information obtained from both the patient and hospital discharge information, and inaccurate in cases of disagreement.

\section{Patients'satisfaction}

Satisfaction with care received was assessed with a single question for each of the selected professional healthcare services. For three interrelated reasons we measured satisfaction with a single question because: (a) our

Table 1 Summary of types of assessment of characteristics of patients, their care, and their satisfaction

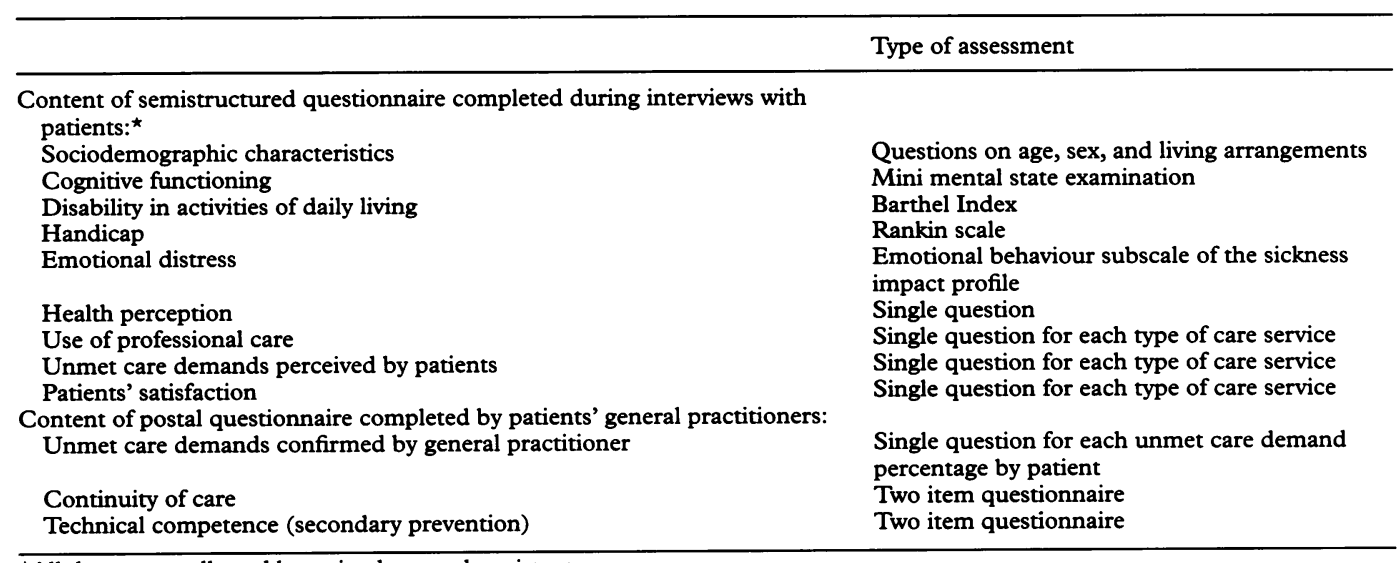

*All data were collected by trained research assistants. 
questionnaire was already long, as our study was primarily focused on the assessment of a wide range of health outcomes; $(b)$ we measured patients' satisfaction for a wide variety of health care services as after stroke care is extensive; and (c) stroke patients have a limited capability to undergo lengthy interviews. For each type of care, the patient could indicate whether he or she found this care excellent or good (satisfied with care) or moderate, poor, or very poor (dissatisfied with care). The moderate level of satisfaction was added to the dissatisfaction category because patients are often reluctant to be critical about their health care received. ${ }^{14}$

As the patient's chance of being dissatisfied with one or more of the care services is associated with the number of care services received, we corrected the level of dissatisfaction by dividing the total number of types of care about which the patient was dissatisfied by the total number of types of care the patient received. For example, a patient who received four types of care and was dissatisfied with two of these, received a personal dissatisfaction score of $2 / 4=0.5$; a patient who received three types of care and was dissatisfied with two of these, received a personal dissatisfaction score of $2 / 3=0.7$. Afterwards, we calculated the mean group level of dissatisfaction. At the group level dissatisfaction was defined as a score higher than the group mean, whereas satisfaction reflects a score lower than the group mean.

\section{STATISTICAL ANALYSIS}

To identify characteristics of patients and care that are associated with patients' satisfaction at the group level $\chi^{2}$ tests were used. Three care characteristics are the exclusive responsibility of the general practitioner - namely, continuity of care (the number of weeks since the last contact between patient and general practitioner), and two sorts of secondary prevention (the general practitioner's awareness of the patient's hypertension and knowledge of the patient's use of antithrombotic medication). Therefore, the relation between these three care characteristics and patients' dissatisfaction was not analysed at an aggregated level, but specifically for general practitioner care.

As contact frequency between patient and general practitioner is probably influenced by the patients' functional health, additional analysis was performed in which the association between dissatisfaction with general practitioner care and continuity of care was adjusted for level of disability (severe disability was defined as a score of $<17$ on the Barthel index).

As it was expected that characteristics of both patients and care were mutually related for example, there would be interrelations between age, disability, perceived health, and unmet care demands - the effects of these factors on patient's dissatisfaction were additionally analysed with multivariate logistic regression. Age, disability, handicap, and perception of health, as well as the significant characteristics of the patients and of care $(P \leq$ 0.10 ) identified from univariate analysis were forced into the model. The effect sizes were expressed as odds ratios (ORs) (calculated as the antilogarithm of the regression coefficients of the logistic regression model) with $95 \%$ confidence intervals ( $95 \% \mathrm{CIs}$ ). The OR indicates how much more likely (or unlikely) dissatisfaction with care is in patients with the characteristic of interest than in patients without that characteristic.

To investigate the consequences of including a moderate level of patients' satisfaction in the dissatisfaction category, analysis of varience was repeated with the moderate level of satisfaction included in the satisfaction category. All analyses were done with SPSS/PC+ Statistics 5.0.2 (SPSS, Illinois, USA).

The study was performed from mid-1991 to mid-1992 and was approved by the medical ethics committees of the participating centres. Informed consent was given by all patients.

\section{Results}

From the original cohort of 760 stroke patients, data on patients' satisfaction were collected from 327 non-institutionalised patients. (258 Patients died after stroke; 103 patients were readmitted to hospitals, stayed in rehabilitation centres, or lived in nursing homes; 17 patients declined to participate in the study; and 33 patients could not be interviewed because of serious communication disorders. For 22 communicative patients no data on patients' satisfaction could be collected because they were not capable of undergoing a lengthy interview). Of the 327 general practitioners, 298 returned the postal questionnaire (response rate $91 \%$ ).

\section{CHARACTERISTICS OF PATIENTS}

Table 2 shows the characteristics of the patients in the study group. The median (range) age was $71(20-94)$ years; $180(55 \%)$ were men and of the $283(87 \%)$ who lived independently $196(69 \%)$ lived with a partner. To avoid unacceptably long interviews we did not measure cognitive function in 29 (9\%) patients, whereas in $20(6 \%)$ emotional distress could not be assessed. Among all patients, 25 $(7 \%)$ were not able to score the one item question on perceived health. A few of the patients $(52(16 \%))$ were severely disabled in activities of daily living, whereas almost half of the patients (146 (45\%)) were substantially handicapped.

\section{CHARACTERISTICS OF CARE}

Table 3 shows the frequency distributions of unmet care demands perceived by patients, unmet care demands confirmed by their general practitioners, continuity of care, and secondary prevention six months after stroke. In all, a quarter of the patients perceived unmet care demands (85 (26\%)); 44 of these patients had an unmet demand for two or more types of care. Of the 85 patients who had unmet care demands, 49 patients $(58 \%)$ had their unmet demands confirmed by their general practi- 
Table 2 Characteristics of patients six months after stroke $(n=327)$

\begin{tabular}{|c|c|c|c|}
\hline Characteristics & Differentiation of characteristic & Definition & $\begin{array}{l}\text { Patients } \\
n(\%)\end{array}$ \\
\hline Age $^{\star}$ & $\begin{array}{l}\text { Younger } \\
\text { Older }\end{array}$ & $\begin{array}{l}\leq 71 \\
>71\end{array}$ & $\begin{array}{l}158(48) \\
169(52)\end{array}$ \\
\hline Sex & $\begin{array}{l}\text { Male } \\
\text { Female }\end{array}$ & & $\begin{array}{l}180(55) \\
147(45)\end{array}$ \\
\hline Living arrangement & $\begin{array}{l}\text { Independent } \\
\text { Partner } \\
\text { Alone } \\
\text { Protected }^{\dagger}\end{array}$ & & $\begin{array}{l}283(87) \\
196(69) \\
87(31) \\
44(13)\end{array}$ \\
\hline Cognitive functioning & $\begin{array}{l}\text { Normal } \\
\text { Dementia } \\
\text { Unknown }\end{array}$ & $\begin{array}{l}\geq 24 \text { MMSE } \\
<24 \text { MMSE }\end{array}$ & $\begin{array}{l}252(77) \\
46(14) \\
29(9)\end{array}$ \\
\hline Disability $^{\ddagger}$ & $\begin{array}{l}\text { Absent or mild } \\
\text { Severe } \\
\text { Unknown }\end{array}$ & $\begin{array}{l}\geq 17 \text { Barthel index } \\
<17 \text { Barthel index }\end{array}$ & $\begin{array}{l}273(83) \\
52(16) \\
2(1)\end{array}$ \\
\hline Handicap ${ }^{\star}$ & $\begin{array}{l}\text { Absent or mild } \\
\text { Severe } \\
\text { Unknown }\end{array}$ & $\begin{array}{l}\text { < } 3 \text { Rankin scale } \\
\geq 3 \text { Rankin scale }\end{array}$ & $\begin{array}{l}177(54) \\
146(45) \\
4(1)\end{array}$ \\
\hline Emotional distress ${ }^{\star}$ & $\begin{array}{l}\text { Normal } \\
\text { Distressed } \\
\text { Unknown }\end{array}$ & $\begin{array}{l}\leq 0.10 \text { SIP subscale } \\
>0.10 \text { SIP subscale }\end{array}$ & $\begin{array}{l}153(47) \\
154(47) \\
20(6)\end{array}$ \\
\hline Health perception & $\begin{array}{l}\text { Healthy } \\
\text { Unhealthy } \\
\text { Unknown }\end{array}$ & & $\begin{array}{l}166(51) \\
136(42) \\
25(7)\end{array}$ \\
\hline
\end{tabular}

ऋ Age, handicap, and emotional distress were dichotomised at the median.

${ }^{\dagger}$ For example, service flat, home for elderly people.

₹ Disability was dichotomised at the 75th percentile. MMSE = mini mental state examination; SIP = sickness impact profile.

tioners. The time interval since the last contact health care used ranged from general between general practitioner and patient was more than three weeks in over half of the patients $(170(52 \%))$. The general practitioners of $217(67 \%)$ patients were not informed about the patient's discharge from hospital or rehabilitation centre, the general practitioners of $20(6 \%)$ patients were unaware of the patient's hypertension, and the general practitioners of $33(10 \%)$ patients had an inaccurate knowledge of their patient's use of antithrombotic medication. In 109 patients (33\%) we could not assess the accuracy of the general practitioner's knowledge, because there was inconsistency between the reported antithrombotic medication as mentioned by the patient and the information on the hospital chart, or there were data missing from one of the three sources (general practitioner, patient, and hospital chart).

PATIENTS' SATISFACTION

Table 4 shows the frequency distributions of (temporary) care received and patients' satisfaction. In the period between discharge from the hospital and six months after stroke, practitioner care (324 (99\%)) to mental care (54 (17\%)). Besides general practitioner care, patients made particular use of physiotherapy $(214(65 \%))$ and home help $(136(42 \%)) .^{20}$ Most dissatisfaction was expressed by patients about general practitioner care (69 (21\%)), occupational therapy (24 (23\%)), and home help (29 (21\%)). Altogether, 131 (40\%) patients were dissatisfied with at least one type of care, $26(8 \%)$ were dissatisfied with two, and $14(4 \%)$ were dissatisfied with three or more.

Table 5 shows the relations between patients' satisfaction on the one hand and characteristics of patients and care on the other. Stroke patients who were dissatisfied with care received did not differ significantly from satisfied patients in sex, cognitive function, disability, handicap, perceived health, unmet care demands confirmed by their general practitioners, and continuity of care (whether or not the general practitioner was informed about the patient's discharge from the hospital or rehabilitation centre). Furthermore, we could not find an association

Table 3 Distribution of unmet care demands perceived by patients, unmet care demands confirmed by their general practitioners (GPs), continuity of care, and secondary prevention at six months after stroke $(n=327)$

\begin{tabular}{|c|c|c|c|}
\hline Characteristics of care & Differentiation of characteristic & Definition & $\begin{array}{l}\text { Patients } \\
n(\%)\end{array}$ \\
\hline Unmet care demand perceived by patient & $\begin{array}{l}\text { No unmet care demand } \\
\text { Unmet care demand } \\
\text { Unknown }\end{array}$ & & $\begin{array}{l}241(74) \\
85(26) \\
1(0)\end{array}$ \\
\hline Unmet care demand confirmed by GP $(n=85)^{\star}$ & $\begin{array}{l}\text { No unmet care demand } \\
\text { Unmet care demand } \\
\text { Unknown }\end{array}$ & & $\begin{array}{l}25(29) \\
49(58) \\
11(13)\end{array}$ \\
\hline GP informed about patient's discharge & $\begin{array}{l}\text { Informed } \\
\text { Not informed } \\
\text { Unknown }\end{array}$ & & $\begin{array}{l}63(19) \\
217(67) \\
47(14)\end{array}$ \\
\hline Last contact between patient and $\mathrm{GP}^{\ddagger}$ & $\begin{array}{l}\text { Recently } \\
\text { Longer time ago } \\
\text { Unknown }\end{array}$ & $\begin{array}{l}<3 \text { weeks } \\
\geq 3 \text { weeks }\end{array}$ & $\begin{array}{l}122(37) \\
170(52) \\
35(11)\end{array}$ \\
\hline GP aware of patient's hypertension & $\begin{array}{l}\text { Aware } \\
\text { Not aware } \\
\text { Unknown }\end{array}$ & & $\begin{array}{l}276(85) \\
20(6) \\
31(9)\end{array}$ \\
\hline $\begin{array}{l}\text { GP's knowledge of patient's use of } \\
\text { antithrombotic medication }\end{array}$ & $\begin{array}{l}\text { Accurate knowledge } \\
\text { Inaccurate knowledge } \\
\text { Unknown }\end{array}$ & & $\begin{array}{l}185(57) \\
33(10) \\
109(33)\end{array}$ \\
\hline
\end{tabular}

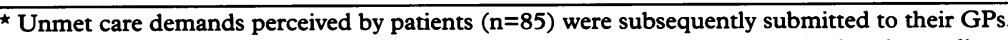

${ }^{\ddagger}$ Number of weeks since last contact between patient and GP was dichotomised at the median. 
Table 4 Distribution of (temporary) care and patients'satisfaction in the period between hospital discharge and six months after stroke $(n=327)$

\begin{tabular}{|c|c|c|c|}
\hline Care services & $\begin{array}{l}\text { Patients who used } \\
\text { care } \\
n(\%)\end{array}$ & $\begin{array}{l}\text { Dissatisfaction * or } \\
\text { satisfaction }\end{array}$ & $\begin{array}{l}\text { Patients } \\
n(\%)\end{array}$ \\
\hline GP care & $324(99)$ & $\begin{array}{l}\text { Satisfied } \\
\text { Dissatisfied } \\
\text { Unknown }\end{array}$ & $\begin{array}{l}227(70) \\
69(21) \\
28(9)\end{array}$ \\
\hline Physiotherapy & $214(65)$ & $\begin{array}{l}\text { Satisfied } \\
\text { Dissatisfied } \\
\text { Unknown }\end{array}$ & $\begin{array}{l}188(88) \\
21(10) \\
5(2)\end{array}$ \\
\hline Occupational therapy & $104(32)$ & $\begin{array}{l}\text { Satisfied } \\
\text { Dissatisfied } \\
\text { Unknown }\end{array}$ & $\begin{array}{l}80(77) \\
24(23) \\
0(0)\end{array}$ \\
\hline Speech therapy & $78(24)$ & $\begin{array}{l}\text { Satisfied } \\
\text { Dissatisfied } \\
\text { Unknown }\end{array}$ & $\begin{array}{l}69(88) \\
3(4) \\
6(8)\end{array}$ \\
\hline Mental care & $54(17)$ & $\begin{array}{l}\text { Satisfied } \\
\text { Dissatisfied } \\
\text { Unknown }\end{array}$ & $\begin{array}{l}37(69) \\
9(16) \\
8(15)\end{array}$ \\
\hline Social care & $70(22)$ & $\begin{array}{l}\text { Satisfied } \\
\text { Dissatisfied } \\
\text { Unknown }\end{array}$ & $\begin{array}{l}45(64) \\
11(16) \\
14(20)\end{array}$ \\
\hline Nursing care & $90(28)$ & $\begin{array}{l}\text { Satisfied } \\
\text { Dissatisfied } \\
\text { Unknown }\end{array}$ & $\begin{array}{l}69(80) \\
17(14) \\
4(6)\end{array}$ \\
\hline Home help & $136(42)$ & $\begin{array}{l}\text { Satisfied } \\
\text { Dissatisfied } \\
\text { Unknown }\end{array}$ & $\begin{array}{l}102(75) \\
29(21) \\
5(4)\end{array}$ \\
\hline Day care & $62(19)$ & $\begin{array}{l}\text { Satisfied } \\
\text { Dissatisfied } \\
\text { Unknown }\end{array}$ & $\begin{array}{l}53(86) \\
5(8) \\
4(6)\end{array}$ \\
\hline
\end{tabular}

^ Patient's satisfaction was measured with a five point scale; excellent or good (satisfaction), moderate, poor or very poor (dissatisfaction). $\mathrm{GP}=$ general practitioner.

between patients' satisfaction with general practitioner care and continuity of contact between patient and general practitioner secondary prevention. However, dissatisfied patients were more often emotionally distressed and more often perceived unmet care demands than satisfied patients.

Additional analysis of the relation between patients' dissatisfaction with general practitioner care and continuity of care (contact frequency between patient and general practitioner) in which continuity was corrected for the patient's level of disability, did not change the results $(P=0.44)$. More detailed analyses of patients' satisfaction with each of the other care services showed identical patterns to the results presented (the results are available on request).

When age, disability, handicap, health perception, and the other characteristics of patients and care identified as significant by univariate analysis were entered into the multivariate logistic regression model, the results showed that emotional distress (OR 1.8) and specifically unmet care demands perceived by patients (OR 3.2) were still the main variables associated with patients' dissatisfaction (table 6). Repeated analysis with moderate patients' satisfaction included in the satisfaction category gave the same results.

\section{Discussion}

Forty per cent of the study sample was dissatisfied with at least one type of care. Six months after stroke, patients' dissatisfaction is primarily associated with emotional distress and unmet care demands as perceived by patients. We could not show that patients' satisfaction with general practitioner care is associated with continuity of care and secondary prevention.

However, some caution is needed in interpreting the results. Firstly, we measured patients' satisfaction for a wide variety of health care services because care after stroke is extensive. However, for reasons mentioned earlier, we measured patients' satisfaction with a single question. Therefore, we know little about which specific care characteristics were actually rated by the patients. Satisfaction encompasses a broad range of domains such as availability, communication, technical competence, etc. ${ }^{2122}$ It may be possible that patients' dissatisfaction is also related to care characteristics other than those we have assessed. Secondly, compared with multidimensional questionnaires, scores for general satisfaction with the quality of health care may be too optimistic. ${ }^{1}$ For this reason, we have considered a moderate score of satisfaction to be dissatisfac-

Table 5 Relative frequencies ( $n(\%)$ ) of characteristics of patients and care; differences between patients who are dissatisfied and satisfied with the care received $(n=327)$

\begin{tabular}{|c|c|c|c|}
\hline Characteristics of patients and care & $\begin{array}{l}\text { Dissatisfaction at an } \\
\text { aggregated level } \\
(n=120)\end{array}$ & $\begin{array}{l}\text { Satisfaction at an } \\
\text { aggregated level } \\
(n=207)\end{array}$ & P value \\
\hline \multicolumn{4}{|l|}{ Characteristics of patients: } \\
\hline Older age ${ }^{\dagger}$ & $57 / 120(48)$ & $112 / 207(54)$ & 0.30 \\
\hline Male & $65 / 120(54)$ & $115 / 207(56)$ & 0.90 \\
\hline Living independently & $106 / 120(88)$ & $177 / 207(86)$ & 0.58 \\
\hline Living alone & $31 / 120(26)$ & $56 / 207(27)$ & 0.70 \\
\hline Dementia & $20 / 120(17)$ & $26 / 207(13)$ & 0.33 \\
\hline Severe disability ${ }^{\ddagger}$ & $23 / 120(19)$ & $29 / 205(14)$ & 0.30 \\
\hline Severe handicap ${ }^{\dagger}$ & $59 / 119(50)$ & $87 / 204(43)$ & 0.27 \\
\hline Emotional distress ${ }^{\dagger}$ & $70 / 112(63)$ & $84 / 195(43)$ & $<0.01$ \\
\hline Feeling unhealthy & $55 / 109(51)$ & $81 / 193(42)$ & 0.19 \\
\hline \multicolumn{4}{|l|}{ Characteristics of care: } \\
\hline Unmet care demand perceived by patient & $50 / 120(42)$ & $35 / 206(17)$ & $<0.01$ \\
\hline Unmet care demand confirmed by GP & $27 / 43(63)$ & $22 / 31(71)$ & 0.63 \\
\hline GP was not informed about patient's discharge & $79 / 100(79)$ & $138 / 180(77)$ & 0.76 \\
\hline GP care characteristics: Number & 69 & 227 & \\
\hline Last contact $\mathrm{GP} \geq 3$ weeks ago $^{\dagger}$ & $39 / 61(64)$ & $116 / 206(56)$ & 0.36 \\
\hline GP was not aware of patient's hypertension & $5 / 62(8)$ & $13 / 207(6)$ & 0.84 \\
\hline $\begin{array}{l}\text { GP had inaccurate knowledge of patient's use of } \\
\text { antithrombotic medication }\end{array}$ & $9 / 47$ (19) & $24 / 157$ (15) & 0.69 \\
\hline \multicolumn{4}{|c|}{$\begin{array}{l}\text { ॠ Firstly, at a personal level the patient's amount of dissatisfactions was divided by the total number of care types received; then } \\
\text { the mean group level of dissatisfaction was calculated. At group level dissatisfaction was defined as a score higher than the group } \\
\text { mean, whereas satisfaction reflected a score lower than the group mean. } \\
\text { t Continuous variables were dichotomised at the median. } \\
\text { ‡ Disability was dichotomised at the } 75 \text { th percentile. } \\
\text { Differences between frequencies were analysed with } \chi^{2} \text { tests. Missing values were omitted from this analysis. GP = general } \\
\text { practitioner. }\end{array}$} \\
\hline
\end{tabular}


Table 6 Logistic regression model to explain patients' dissatisfaction ( $n=327)$

\begin{tabular}{llll}
\hline & \multicolumn{3}{l}{ Patients' dissatisfaction } \\
\cline { 2 - 4 } & ORs & $95 \%$ CIs & Pvalue $^{*}$ \\
\hline Characteristics of & & & \\
patients: $^{\dagger}$ & & & \\
Older age $_{\text {Severe disability }}$ & 0.8 & $(0.5-1.3)$ & 0.33 \\
Severe handicap & 1.7 & $(0.3-1.5)$ & 0.36 \\
Emotional distress & 1.8 & $(0.9-1.7)$ & 0.28 \\
Feeling unhealthy & 1.1 & $(0.7-1.8)$ & 0.03 \\
Characteristics of care: ${ }^{\dagger}$ & & & 0.72 \\
Unmet care demand & 3.2 & $(1.8-5.7)$ & $<0.01$ \\
perceived by patient & & & \\
\hline
\end{tabular}

ऋ Calculated with Wald statistics.

${ }^{\dagger}$ Reference group are patients with the opposite or none of these characteristics.

tion. Thirdly, we evaluated stroke patients' satisfaction with a cross sectional study design at six months after stroke and we can only speculate on the longitudinal impact of characteristics of patients and care on satisfaction. Hall and colleagues have shown that an improvement in the patient's health is associated with a higher level of satisfaction at a later point in time (but not vice versa). ${ }^{9}$ Furthermore, it may be possible that patients' satisfaction at six months after stroke is influenced by emotional distress due to, for example, the end of rehabilitative therapies or still unresolved coping problems. ${ }^{23-25}$ A longer time after stroke, the patients' satisfaction might be less influenced by such psychological factors. On the other hand, long term data on patients' satisfaction after stroke will be limited to long term survivors - namely, the healthiest patients.

Patients were particularly dissatisfied with general practitioner care, occupational therapy, and home help. The relatively high dissatisfaction with general practitioner care has also been reported by others. ${ }^{72}$ It is suggested that the relatively high dissatisfaction with physicians, compared with, for example, nurses, may be explained by the patients' viewpoint that physicians have the supreme authority and final responsibility in all healthcare matters. ${ }^{726}$ Perhaps the home help interferes directly with the patient's daily routine and privacy, and hence is more likely to be a source of criticism. ${ }^{27}$

It has been hypothesised that impaired health may have a negative influence on the patient's attitude toward many aspects of life, health care included. ${ }^{89}$ We could not find an association between patients' dissatisfaction and objective impaired functional health. However, emotionally distressed patients and patients who perceived unmet care demands were more often dissatisfied, even after adjustment for age, functional health, and health perception. These results are in agreement with other research findings. ${ }^{528} 29$ Some authors have suggested that an emotionally distressed patient may have demands which the healthcare system does not or cannot meet. ${ }^{51429}$ For example, for stroke patients it may be difficult to accept that in the long run the efficacy of rehabilitation interventions is limited. ${ }^{23-25}$ From a care giver's point of view, dissatisfaction is then due to unreasonable expectations of the healthcare system. Also, providers of health care may respond to frustrated and distressed patients in ways that produce even more dissatisfaction. ${ }^{529}$

Furthermore, we could not show that patients' satisfaction with general practitioners' care is associated with continuity of care and secondary prevention; two care characteristics broadly accepted by professional care givers as important indicators of quality of long term care after stroke. ${ }^{14}{ }^{15}$ It seems likely that patients and professionals focus on different aspects of care and also use different criteria when assessing quality of care. Professional views probably tend to focus on technical aspects of care (such as the use of antithrombotic medication), whereas patients' quality assessment may be more based on interpersonal aspects of care. ${ }^{15}$ Therefore, it is advisable to use the plural term "qualities of care", and to take both patients' and professionals' viewpoints into account.

In view of these results measurement of satisfaction should ideally be multidimensional as well as multidisciplinary. To enhance our insight further into the construct of patients' satisfaction, discussion should take place about the relative weight that should be given to patients' satisfaction as an indicator of quality of care, compared with other quality indicators such as continuity of care and technical competence. More research is needed to find which dimensions of quality of care are considered to be the most important by stroke patients and professional care givers.

This study was funded by The Netherlands Heart Foundation (NHS 40.004), Ontwikkelingsgeneeskunde (OG 1991-037), and The Netherlands Organisation of Scientific Research, Medical Science (NWO/KWAZO 900-571-032).

1 Lewis JR. Patient views on quality care in general practice: literature review. Soc Sci Med 1994;39:655-70.

2 Lohr KN. Outcome measurement: concepts and questions. Inquiry 1988;25:37-50.

3 Bos GAM van den, Limburg LCM. Public health and chronic diseases [guest editorial]. Eur 7 Public Health 1995;5:1-2.

4 Williams B. Patient satisfaction: a valid concept? Soc Sci Med 1994;38:50916.

5 Cleary PD, McNeil BJ. Patient dissatisfaction as an indicator of quality care. Inquiry 1988;25:25-36.

6 Davies RA, Ware JE. Involving consumers in quality of care assessment. Health Affairs 1988;7:33-48.

7 Oberst MT. Patients' perceptions of care. Measurement of quality and satisfaction. Cancer 1984;53:2366-73.

8 Sensky T, Catalan J. Asking patients about their treatment. BMf 1992;305:1 109-10.

9 Hall JA, Milburn MA, Epstein AM. A causal model of health status and satisfaction with medical care. Med Care 1993;31:84-94.

10 Herman B, Leyten AMC, van Luijk JM, Frenken CWGM, Opde Coul AAW, Schulte BPM. Epidemiology of stroke in Tilburg the Netherlands. The populationbased stroke Tilburg, the Netherlands: The populationbased stroke incidence register: 2 . Incidence, initial clinical picture and medical care, and three-week based fatality. Stroke
1982;13:629-34.

11 Niessen LW, Barendregt JJ, Bonneux L, Koudstaal PJ. Stroke trends in an aging population. Stroke 1993;24:931-

12 Silliman RA, Wagner EH, Fletcher RH. The social and functional consequences of stroke for elderly patients. Stroke 1987;18:200-3.

13 Ebrahim S, Barer D, Nouri F. An audit of follow-up services for stroke patients after discharge from hospital. Inter national Disability Studies 1987;9:103-5.

14 Hjortdahl P, Lerum E. Continuity of care in general practice: effect on patient satisfaction. $B M \mathcal{F}^{1992}$; 304:1287-90

15 Antiplatelet Trialists' Collaboration. Collaborative overview of randomised trials of antiplatelet therapy. 1: Prevention of death, myocardial infarction, and stroke by prolonged antiplatelet therapy in various categories of patients. $B M^{f}$ 1994;308:81-106. 
16 Folstein MF, Folstein SE, McHugh PR. "Mini-mental state". A practical method for grading the cognitive state of patients for the clinician. $f$ Psychiatr Res 1975;12:189-98.

17 Wade DT, Collin C. The Barthel ADL index: a standard measure of physical disability? International Disability measure of physical
Studies 1988;10:64-7.

18 Bamford JM, Sandercock PAG, Warlow CP, Slattery J Interobserver agreement for the assessment of handicap in

19 Bergner M, Bobbitt RA, Carter WB, Gilson BS. The sickness impact profile: development and final revision of a health status measure. Med Care 1981;19:787805

20 Haan R de, Limburg M, Meulen J van der, Bos GAM van den. Use of health care services after stroke. Quality in Health Care 1993;2:222-7.

21 Ware JE, Snyder MK, Wright WR, Davies AR. Defining and measuring patient satisfaction with medical care. Evaluation and Program Planning 1983;6:24763.

$22 \mathrm{McC}$ usker J. Development of scales to measure satisfaction and preferences regarding long-term and terminal care.
Med Care 1984;22:476-93.

23 Anderson R. The aftermath of stroke. Cambridge: Cambridge University Press, 1992.

24 Pound P, Gompertz P, Ebrahim S. Patients' satisfaction with stroke services. Clin Rehabil 1994;8:7-17.

25 Pound P, Bury M, Gompertz P, Ebrahim S. Views of survivors of stroke on benefits of physiotherapy. Quality in Health Care 1994;3:69-74.

26 Tagliacozzo DL, Mauksch HO. The patient's view of the patient's role. In: Jaco EG, ed. Patients, physicians and illness, 2nd ed. New York: Free Press, 1972;172-85.

27 Bos GAM van den. Zorgen van en voor chronisch zieken (Care Bos GAM van den. Zorgen van en voor chronisch zieken (Care
for the chronically ill) [dissertation]. Utrecht: Scheltema and Holkema, 1989.

28 Veer de AJE, Bakker de DH. Measuring unmet needs to assess the quality of home health care. International fournal for Quality in Health Care 1994;6:267-74.

29 Greenley JR, Young TB, Schoenherr RA. Psychological distress and patient satisfaction. Med Care 1982;20:373. 